\title{
Naviculectomy as a third way beyond minimally invasive and extensive soft tissue releases for ambulatory children with complex congenital vertical talus: A technical note
}

\author{
Ahmad S. Aly, (D) Shady Samir, (D) Shady Mahmoud, (D) Tamer A. El-Sobky* \\ Division of Pediatric Orthopedics, Department of Orthopedic Surgery, Faculty of Medicine, Ain \\ Shams University, Cairo, Egypt. * Correspondence: tamer.ahmed@med.asu.edu.eg
}

\begin{abstract}
We investigated the radioclinical outcomes of naviculectomy and limited/tailored soft-tissue releases in a short series of ambulatory children with complex/intractable congenital vertical talus subsets namely neglected, multiple operated and recurrent patients. We postulated that this technique will yield satisfactory radioclinical outcomes and minimal complications because it avoids extensive surgical release/trauma that is otherwise classically recommended for complex congenital vertical talus (CVT). The cohort consisted of five -four boys, one girl- complex CVT children with neglected, multiple operated and/or recurrent subsets. Patients were included if manipulative casting techniques were deemed unlikely to produce a plantigrade foot. Patients underwent naviculectomy with variable on-demand limited soft tissue releases. Two patients had bilateral affection and two had a non-idiopathic aetiology. The mean age was 5.2 years (4 to 6.25) and mean follow-up was 2.3 years (1 to 3). We reported satisfactory outcomes as per foot posture, function, overall parent satisfaction including pain and radiography per lateral views of talar-axis-first metatarsal base angle on the short/intermediate term. Whereas manipulative casting is unlikely to yield lasting outcomes in ambulatory children with complex subsets of CVT, extensive surgical soft-tissue releases have unfavourable long-term complications. As a substitute, naviculectomy as a form of resection arthroplasty created a practical and affordable third way between manipulative casting with minimally invasive surgery and the extensive surgical soft tissue releases on the short/intermediate term.
\end{abstract}

Keywords: Congenital Foot Deformities; Rigid Flatfoot; Congenital Convex Pes Valgus; Rocker-Bottom Foot; Resection Arthroplasty; Reverse Ponseti Technique

\section{Highlights}

- Naviculectomy with limited soft tissue releases corrects foot posture satisfactory in complex congenital vertical talus (CVT).

- Naviculectomy with limited soft tissue releases restores foot function on short/intermediate term.

- Naviculectomy is also safe and yields a satisfactory functional outcome.

- It can be considered a treatment option in neglected, multiple operated or recurrent CVT.

\section{Introduction}

\footnotetext{
$\mathrm{C}$ ongenital vertical talus (CVT) is a rare foot anomaly. Its typical radioclinical findings include severe and rigid flatfoot with radiographic abnormalities of the talar axis-first metatarsal base angle [1,2]. It is acknowledged that the results of manipulative serial casting with or without minimally invasive surgery are better than extensive soft tissue release respecting surgical trauma inflicted, foot stiffness and pain on the long-term [1-4]. Nevertheless, the use of manipulative techniques is classically suited to children younger than two years regardless of CVT subtype. There is disagreement over the upper age limit for such manipulative treatment when used as a definitive and not as first-line treatment [1, 2, 5-7]. There is indecisiveness regarding outcomes of both manipulative casting and the more extensive soft-tissue releases in patients with
} 
Page 2 of 8

Naviculectomy in CVT

complex CVT subsets namely neglected/late presenting, multiple operated and recurrent subtypes. Such complex congenital foot deformities usually require extensive and devitalizing soft tissue dissection to attain anatomic reduction. Failure to achieve anatomic reduction or deformity recurrence may necessitate revision which can aggravate the amount of surgical trauma inflicted and create a negative risk-to-benefit patient profile $[1,2,8,9]$. Resection arthroplasty or naviculectomy may provide an appealing alternative to the above procedures regarding the less traumatic nature and relative simplicity of its technique $[9,10]$. Historically, naviculectomy was performed as a routine procedure for irreducible CVT children above the age of three months irrespective of ambulatory status and CVT subtype with satisfactory intermediate [11] and long-term results [12]. Upon the successful advent of manipulative casting techniques and minimally-invasive surgery, the use of naviculectomy in "ambulatory" CVT children faded. A recent report revived the use of naviculectomy in two ambulatory children with complex CVT with satisfactory short-term results [10].

We aimed at expanding the above case report [10] in terms of sample size and follow-up period. We hypothesized that naviculectomy represents a viable and less traumatic surgical option that can restore foot posture and function without increasing short/intermediate-term complications.

\section{Patients and Methods}

We retrospectively assessed five ambulatory children (seven feet) with complex CVT subsets. All were ambulatory without walking aids. There were four boys and one girl. All patients were subjected to a standard navicular excision with variable limited/tailored soft tissue releases or 'á la carte' procedures according to El-Sobky et al 2020 [10]. CVT was defined as any rigid foot anomaly that is readily apparent after birth and exhibits a hind foot valgus, ankle equines and forefoot dorsiflexion and abduction. And demonstrates characteristic radiographic abnormalities in the lateral radiographs especially the talar-axis-first metatarsal base angle (TAMBA). The complex subset of ambulatory CVT children may include any of the following in isolation or in combination: neglected/late presenting, multiple operated or recurrence or residual deformity following multiple unsuccessful attempts of manipulative casting techniques, irrespective of the CVT subtype. Two had bilateral affection which were operated in the same sitting. The mean age at time of index procedure, 5.2 years ( 4 to 6.25 ). Three patients had idiopathic CVT while two had non-idiopathic namely congenital arthrogryposis and genetic mutation with undetermined clinical relevance. There were three virgin feet and four recurrent following previous foot surgery. All virgin feet were not subjected to serial manipulative casting (reverse-Ponseti) previously. The universal presenting symptoms were rigid foot deformity, gait difficulties and occasional foot pain. If reverse-Ponseti was deemed unlikely to produce a lasting plantigrade foot, naviculectomy with limited soft-tissue release was indicated.

\section{Surgical technique}

All patients were subjected to a standard navicular excision with variable limited tailored soft-tissue releases or 'á la carte' procedures according to El-Sobky et al 2020 [5]. The choice of the 'á la carte' releases was based on the quality of reduction of the talonavicular joint and subsequent restoration of the medial arch of the foot [Figs. 1, 2]. A direct medial incision was made over the talar head and extended slightly distal. Through it the talonavicular joint was circumferentially released, and plantar calcaneonavicular ligament divided. The bony attachments of the tibialis anterior and tibialis posterior tendons were disinserted in preparation for later rerouting after optimal foot correction. All the bowstringing digital extensors including the peroneus tertious were released through mobilizing a small transverse incision over the anterior ankle. Then, a curved incision was performed over the cuboid through which the extensor digitorum brevis origin, the peroneus brevis tendon and capsule of the calcaneocuboid were released. The tendon Achilles was tenotomised in four feet and lengthened in three feet. The posterior capsule of the ankle was released through a small direct incision. In all patients an attempted reduction of the talonavicular joint was unsuccessful and carried a risk for neurovascular insult. A subperiosteal complete naviculectomy was then made. One arthrogryposis foot received an additional resection of medial cuneiform. A retrograde K-wire was driven through the cuneiform and first ray and foot alignment was restored by maximum forefoot adduction and flexion through the talo-cuneiform pseudoarthrosis, and concomitantly upward pressurizing the talar head. The correction was maintained by advancement of the K-wire proximally. The tibialis anterior tendon was reattached as medial and plantar as possible to the plicated remnants of the talonavicular capsule. Likewise, the tendon of the tibialis posterior was advanced and secured medially. Foot alignment was checked by image intensifier in orthogonal planes. A posterior slab was applied for four weeks followed by a long leg cast for another eight weeks. A rigid ankle-foot-orthosis with a high medial arch was prescribed for six months postoperatively. Patients were clinically assessed by Zorer et al 2002 [13]. The radiographic outcomes included the lateral- talocalcaneal, TAMBA and tibiocalcaneal angles. 
Page 3 of $\mathbf{8}$

\section{Results}

We recorded satisfactory outcomes as per foot posture, function, parent satisfaction and pain. Restored radiographic indices were maintained at mean follow-up of 2.3 years (1-3). The final results are shown [Figs. 3, 4, 5] and [Table 1]. One patient with unilateral idiopathic CVT suffered a calcaneal gait due to Achilles over-lengthening and was reoperated for tendon shortening and percutaneous extensor tenotomy due to digital extensor posture.

\section{Discussion}

In CVT, the exact indications for the vast surgical strategies employed remain undetermined especially respecting the complex subsets of CVT children with useful ambulatory capacity $[1,2,9,14]$. The general consensus among pediatric orthopedic surgeons is that manipulative casting techniques is considered a first line treatment for all forms of club feet irrespective of subtype, age and previous surgeries. Nonetheless, there is considerable uncertainty as to whether it can be used as a definitive treatment option i.e. alleviate the need for additional and extensive surgeries [15-20]. On the other hand the use of extensive surgical soft tissue releases in children with club foot is fraught with impaired foot function, quality of life pain and bone deformations on the long term [20,21]. Similar controversies were echoed in literature on management of CVT children [1, 2, $5-7,10]$. Moreover, vigorous manipulative serial casting techniques usually needed in older children can injure the growing cartilaginous centres of the foot and cause damage to the articular cartilage.

The current rationale behind naviculectomy in CVT presumes that navicular excision will relax the pre-tensioned ligamentous structures especially around the talonavicular joint complex thus creating more room for repositioning of the fore/midfoot on the hindfoot and subsequent reformation of a concave medial arch. Although, additional limited tailored soft-tissue releases may be needed, it remains less traumatic than the classic peri-talar soft-tissue releases. We believe that relative flexibility of the medial arch and foot encountered in most patients of our series is related to the minimal dose of soft-tissue dissection. Dobbs et al, suggested a similar correlation between the dose of soft-tissue release and the degree of functional impairment and stiffness in children with CVT [1,2] and clubfoot [22]. Our favourable short/intermediate term results corroborate those of Robbins 1976 and Clark et al 1977 [11, 12]. Noteworthy, our soft-tissue procedures accompanying naviculectomy mimicked that of Robbins 1976 [11].

Talectomy -another form of resection foot arthroplasty- has been used to address similar complex subsets of clubfoot and CVT alike $[9,23,24]$. However, we believe that talectomy in contrast to naviculectomy, is biomechanically and clinically challenged specifically in ambulatory children on the long-term [Figs. 6, 7]. Firstly, excision of talus can compromise ankle stability, produce an abnormal and weak joint moment through creating a lever arm deformity and disturb load distribution around ankle and foot [25-27]. Secondly, salvage procedures for talectomy as tibiocalcaneal fusion, though successful on short-term [28] are fraught with risk of adjacent joint disease on the long term [29].The rarity of CVT and restriction of our sample size to complex subsets are inherent study limitations. Additionally the indications of surgery and surgical technique were case-based and showed some variations.

\section{Conclusion}

In case both manipulative casting and classic extensive soft-tissue release have been deemed unfeasible to attain a plantigrade foot, naviculectomy with limited/tailored soft-tissue releases can be considered. The functional benefits of naviculectomy in ambulatory children with complex CVT seem to substantially outweigh the risks on the short/intermediate term.

\section{Acknowledgements}

The authors appreciate Woralux Phusoongnern, Neurosurgeon, Neurosurgical unit, Chiangmai Neurological Hospital, Chiangmai, Thailand, for constructing informative and quality medical graphics. The study was approved by the Research Ethics Committee of Faculty of Medicine, Ain Shams University, Egypt number FMASU R 45/2020/2021. This research received no specific grant from any funding agency in the public, commercial or not-for-profit sectors. The authors declare that they have no competing interests.

\section{References}

1. Miller M, Dobbs MB. Congenital vertical talus: etiology and management.J Am Acad Orthop Surg 2015;23:604-611. 
Page 4 of 8

Naviculectomy in CVT

2. Yang JS, Dobbs MB. Treatment of congenital vertical talus: comparison of minimally invasive and extensive soft-tissue release procedures at minimum five-year follow-up. J Bone Joint Surg Am 2015;97:1354-1365.

3. Ramanoudjame M, Loriaut $P$, Seringe R, Glorion C, Wicart P. The surgical treatment of children with congenital convex foot (vertical talus): evaluation of midtarsal surgical release and open reduction. Bone Joint J 2014; 96-B:837-844.

4. Aslani H, Sadigi A, Tabrizi A, Bazavar M, Mousavi M. Primary outcomes of the congenital vertical talus correction using the Dobbs method of serial casting and limited surgery. J Child Orthop 2012; 6:307-311.

5. Eberhardt $\mathrm{O}$, Wirth $\mathrm{T}$, Fernandez FF. [Minimally invasive treatment of congenital foot deformities in infants: new findings and midterm-results]. Orthopade 2013; 42:1001-1007. [Article in German]

6. Wright J, Coggings D, Maizen C, Ramachandran M. Reverse ponseti-type treatment for children with congenital vertical talus: comparison between idiopathic and teratological patients. Bone Joint J 2014; 96-B: 274-278.

7. Chalayon $\mathrm{O}$, Adams A, Dobbs MB. Minimally invasive approach for the treatment of non-isolated congenital vertical talus. $\underline{J}$ Bone Joint Surg Am 2012; 94:e73.

8. Eidelman M, Kotlarsky P, Herzenberg JE. Treatment of relapsed, residual and neglected clubfoot: adjunctive surgery. J Child Orthop 2019;13(3):293-303.

9. Mosca VS. Principles and management of pediatric foot and ankle deformities and malformations. $1^{\text {st }}$ ed. Philadelphia: Lippincott Williams \& Wilkins; 2014.

10. El-Sobky TA, Samir S, Mahmoud S. Naviculectomy for two ambulatory children with intractable congenital vertical talus: redefining the indications of an old technique. J Pediatr Orthop B 2020;29(4):387-391.

11. Robbins H. Naviculectomy for congenital vertical talus. Bull Hosp Joint Dis 1976; 37:77-97.

12. Clark MW, D'Ambrosia RD, Ferguson AB. Congenital vertical talus: treatment by open reduction and navicular excision. J Bone Joint Surg Am 1977;59:816-824.

13. Zorer $G$, Bagatur AE, Dogan A. Single stage surgical correction of congenital vertical talus by complete subtalar release and peritalar reduction by using the Cincinnati incision. J Pediatr Orthop B 2002;11(1):60-67.

14. Sanzarello I, Nanni M, Perna F, Traina F, Faldini C. One-stage release by double surgical approach for neglected congenital vertical talus: results in a series of walking children in Tanzania. J Pediatr Orthop B 2019;28:586-590.

15. Stouten JH, Besselaar AT, Van Der Steen MCM. Identification and treatment of residual and relapsed idiopathic clubfoot in 88 children. Acta Orthop 2018;89:448-453.

16. El-Sayed M. Ilizarov external fixation for management of severe relapsed clubfeet in older children. Foot Ankle Surg 2013; 19(3):177181.

17. Allende V, Paz M, Sanchez S, Lanfranchi L, Torres-Gomez A, Arana E, et al. Complex clubfoot treatment with Ponseti method: a Latin American multicentric study. J Pediatr Orthop 2020;40(5):241-245.

18. El Batti S, Solla F, Clément JL, Rosello O, Oborocianu I, Chau E, et al. Initial treatment of congenital idiopathic clubfoot: Prognostic factors. Orthop Traumatol Surg Res 2016;102(8):1081-1085.

19. Digge V, Desai J, Das S. Expanded age indication for ponseti method for correction of congenital idiopathic talipes equinovarus: A systematic review. J Foot Ankle Surg 2018;57:155-158.

20. Gelfer $Y$, Wientroub S, Hughes K, Fontalis A, Eastwood DM. Congenital talipes equinovarus: a systematic review of relapse as a primary outcome of the Ponseti method. Bone Joint J 2019; 101-B(6):639-645.

21. Alkar F, Louahem D, Bonnet F, Patte K, Delpont M, Cottalorda J. Long-term Results After Extensive Soft Tissue Release in Very Severe Congenital Clubfeet. J Pediatr Orthop 2017;37(7):500-503.

22. Dobbs MB, Nunley R, Schoenecker PL. Long-term follow-up of patients with clubfeet treated with extensive soft-tissue release. J Bone Joint Surg Am 2006;88:986-996.

23. Machida J, Inaba Y, Nakamura N. Management of foot deformity in children. J Orthop Sci 2017; 22:175-183.

24. Chotigavanichaya C, Ariyawatkul T, Eamsobhana P, Kaewpornsawan K. Results of primary talectomy for clubfoot in infants and toddlers with arthrogryposis multiplex congenita. J Med Assoc Thai 2015; 98 (Suppl 8):S38-S41.

25. Ghanem I, Massaad A, Assi A, Rizkallah M, Bizdikian AJ, El Abiad R, et al. Understanding the foot's functional anatomy in physiological and pathological conditions: the calcaneopedal unit concept. J Child Orthop 2019; 13:134-146.

26. Bozkurt M, Apaydin N, Gursoy S, Tubbs RS. Functional Anatomy of the Ankle. In: Doral M., Karlsson J. (eds) Sports Injuries. Springer, Berlin, Heidelberg, 2014. DOI: https://doi.org/10.1007/978-3-642-36801-1 277-2

27. Ozcan O, Karapinar H, Boya H, Uyulgan B, Gunal I. The biomechanical effects of talectomy on the foot. J Am Podiatr Med Assoc 2006;96:495-498.

28. Hacen MME, Sghair YM, Biha N, Aw A, Trigui M, Né C. [Clubfoot in adult patients treated with tibiocalcaneal arthrodesis: about two cases (3 feet)]. Pan Afr Med J 2018;30:222. [Article in French].

29. Nicomedez FP, Li YH, Leong JC. Tibiocalcaneal fusion after talectomy in arthrogrypotic patients. J Pediatr Orthop 2003; 23:654-657. 
Page 5 of 8

Naviculectomy in CVT

\section{Tables}

Table 1: Final radioclinical outcomes of CVT children

\begin{tabular}{|c|c|c|c|c|c|c|c|c|}
\hline \multicolumn{3}{|c|}{ Clinical outcomes* } & \multicolumn{6}{|c|}{ Radiological outcomes ${ }^{ \pm}$} \\
\hline \multirow[b]{2}{*}{$\begin{array}{c}\text { CVT type, FU } \\
\text { (Yr) }\end{array}$} & \multirow[b]{2}{*}{ Preoperative } & \multirow[b]{2}{*}{ Postoperative } & \multicolumn{3}{|c|}{ Preoperative } & \multicolumn{3}{|c|}{ Postoperative } \\
\hline & & & $\begin{array}{c}\text { Talocalcaneal } \\
\text { angel }\end{array}$ & TAMBA & $\begin{array}{c}\text { Tibiocalcaneal } \\
\text { angle }\end{array}$ & $\begin{array}{c}\text { Talocalcaneal } \\
\text { angel }\end{array}$ & TAMBA & $\begin{array}{l}\text { Tibiocalca } \\
\text { neal angle }\end{array}$ \\
\hline Idiopathic (3) & 2 & 12 & 109 & 112 & 110 & 38 & 6 & 58 \\
\hline $\begin{array}{c}\text { Arthrogryposi } \\
\mathrm{s}(2)\end{array}$ & 1 & 10 & 15 & 40 & 104 & 4 & 7 & 85 \\
\hline Idiopathic (3) & R: 1 L: 1 & R: $11 \mathrm{~L}: 12$ & R: 49 L: 44 & R: 52 L: 54 & R: 86 L: 85 & R: 34 L: 28 & R: 6 L: 11 & R: 86 L: 76 \\
\hline $\begin{array}{c}\text { Genetic/syndr } \\
\text { omatic (2.5) }\end{array}$ & $\mathrm{R}: 1 \mathrm{~L}: 2$ & R: 10 L:12 & R: 45 L: 49 & R: 40 L: 45 & R: 92 L: 84 & R: 30 L: 25 & R: 8 L: 6 & R: 70 L: 75 \\
\hline Idiopathic (2) & 2 & $\mathrm{R}: 12$ & $\mathrm{R}: 74$ & $\mathrm{R}: 70$ & R: 110 & $\mathrm{R}: 23$ & $\mathrm{R}: 6$ & $\mathrm{R}: 84$ \\
\hline
\end{tabular}

CVT congenital vertical talus; FU follow-up; TAMBA talar-axis-first metatarsal base angle; * measured according to Zorer et al [13]; \pm all radiological indices recorded in degrees as per lateral views.

\section{Figure legends}
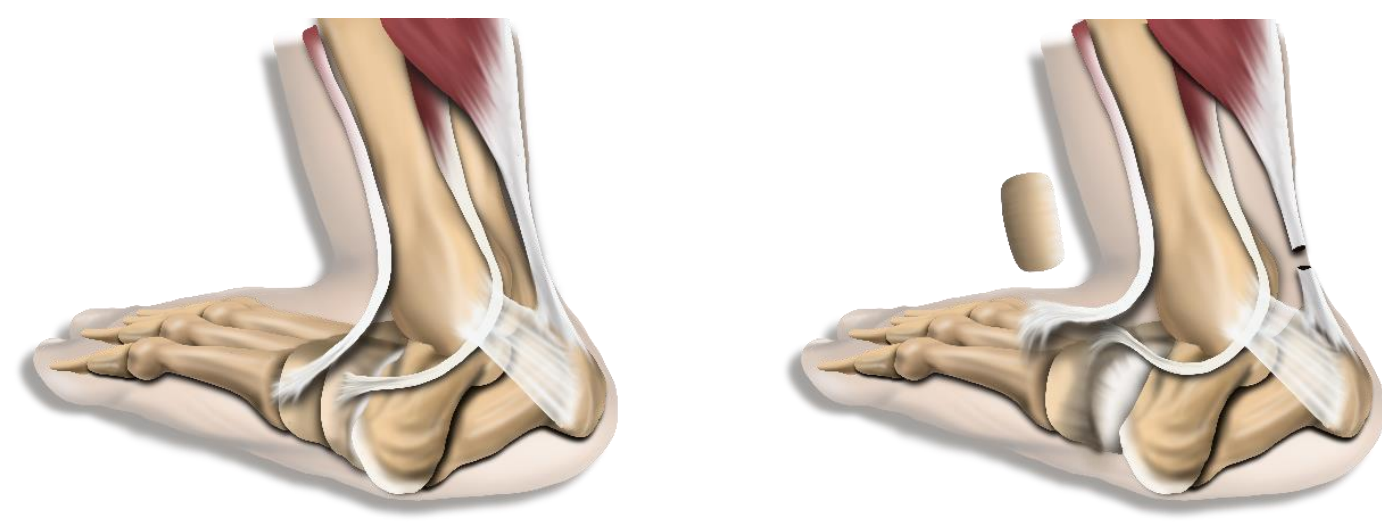

Fig. 1 (A, B): Naviculectomy. (A) Components of CVT deformity. Note the verticality of the talus, dislocated talonavicular joint with overriding navicular, malalignment of tibialis tendons with fore- and midfoot abduction dorsiflexion and shortened Achilles tendon. (B) Technique of naviculectomy. Note the disinsertion of the stretched/lax tibialis tendons and elongation -tenotomy or lengthening- of the tight Achilles tendon. Other 'á la carte' are not shown.

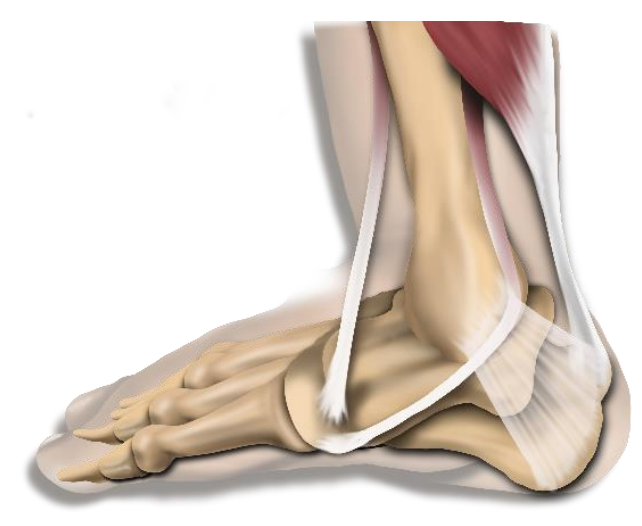

Fig. 2: Final correction. Restoration of concavity of sole of foot through naviculectomy, elongation of Achilles tendon and creation of new articulation between head talus and medial cuneiform and final reinsertion and tensioning of both tibialis tendons. 


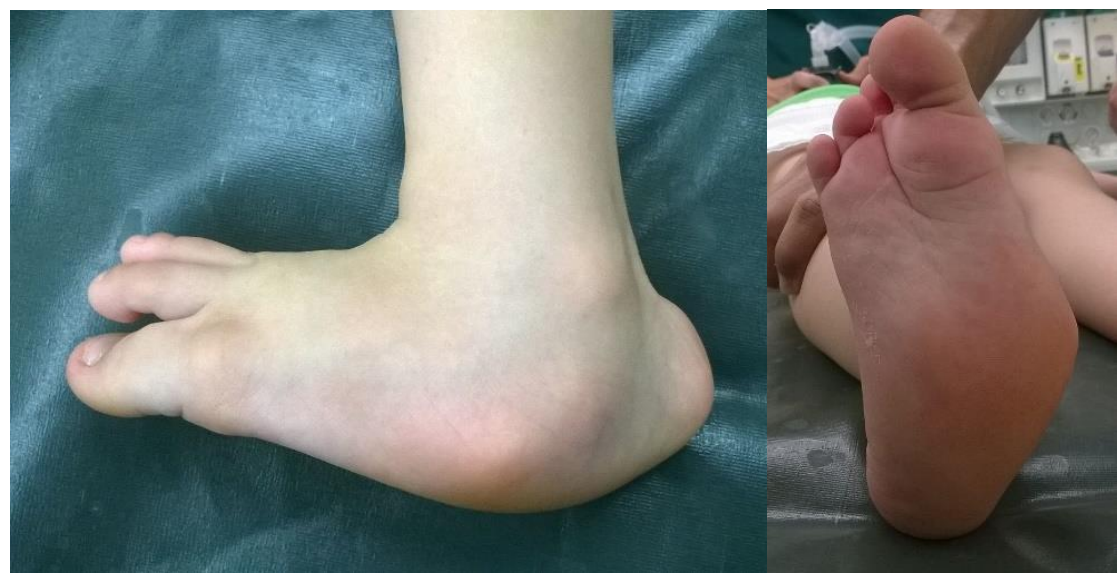

Fig. 3 (A, B): Preoperative clinical photos of 4-year-old boy with right neglected idiopathic CVT. (A) Note marked convex pes-valgus, stretched skin on the medial aspect of foot and pronated fore- and midfoot indicated by depression of the first ray (big toe) and elevation of the other rays (lesser toes). (B) Note the marked forefoot abduction, hindfoot valgus, elongated medial border of foot and shortened lateral border of foot.

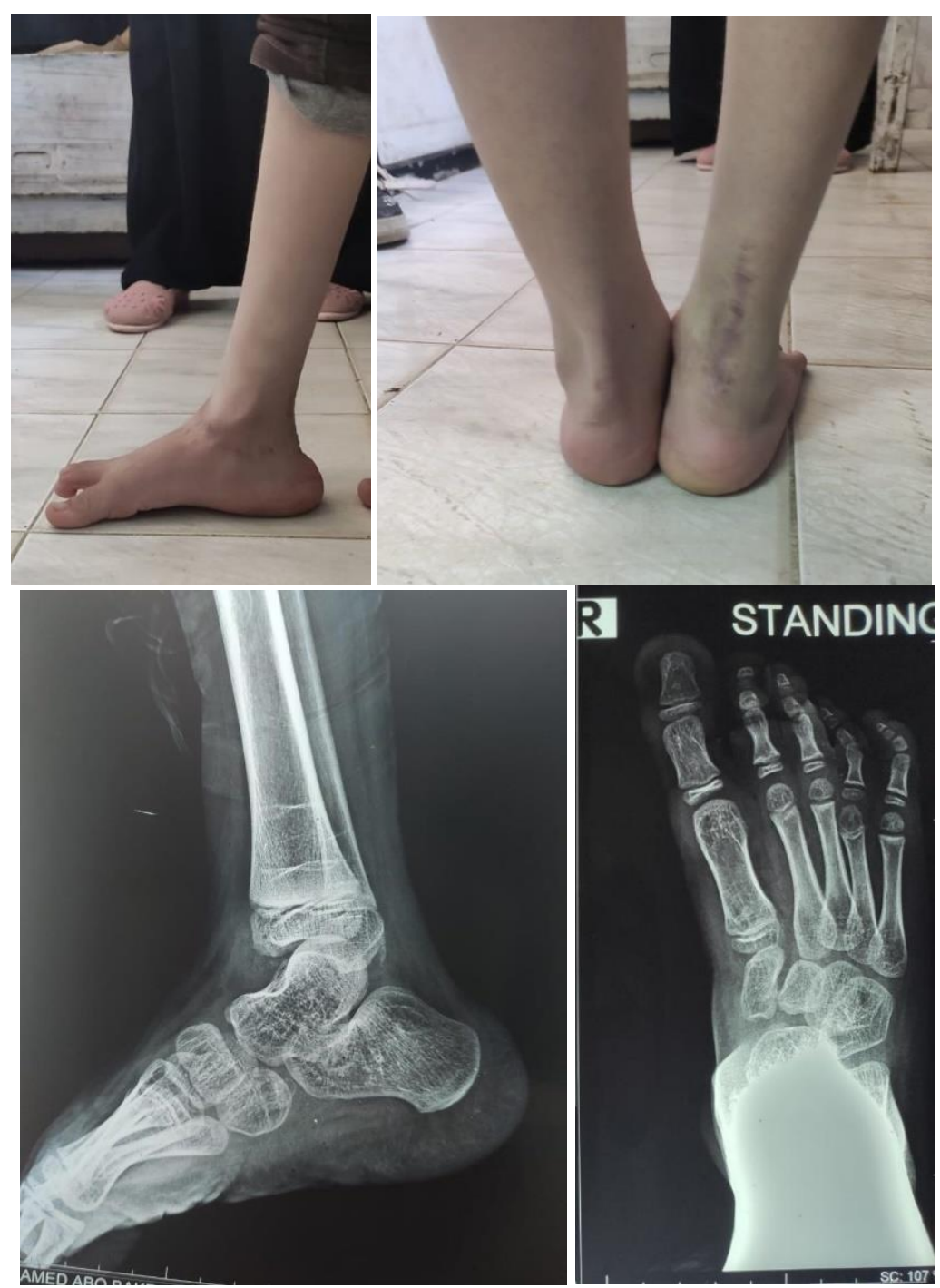

Fig. 4 (A-D): Three-year postoperative photos of previous patient. (A) Note the restored medial foot arch on weight-bearing and straight medial border of foot. (B) Note restoration of hindfoot alignment. (C) Lateral and (D) AP radiographs of the foot show maintenance of the normalized indices despite absence of the navicular. 
Page 7 of 8

Naviculectomy in CVT
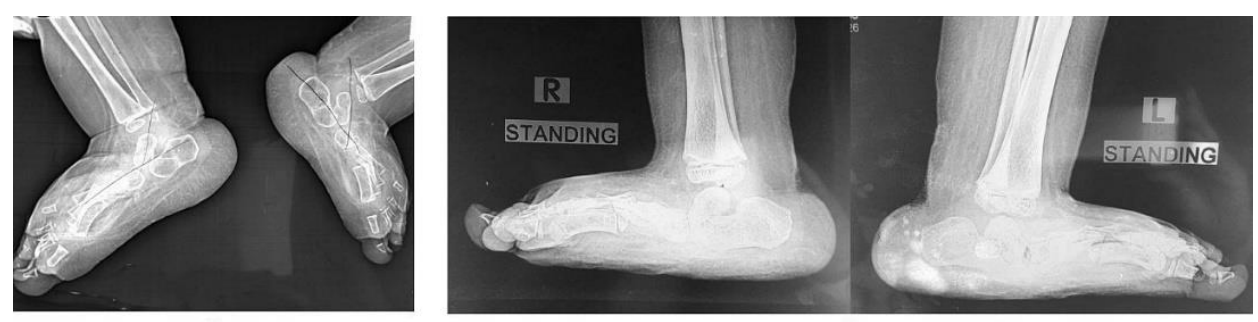

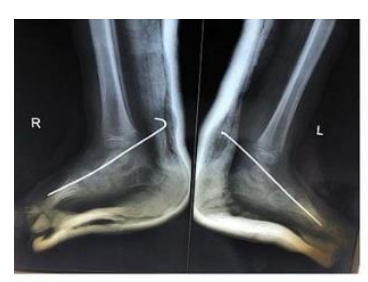

Immediate postoperative

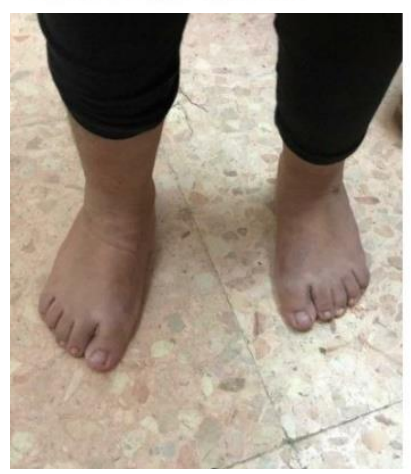

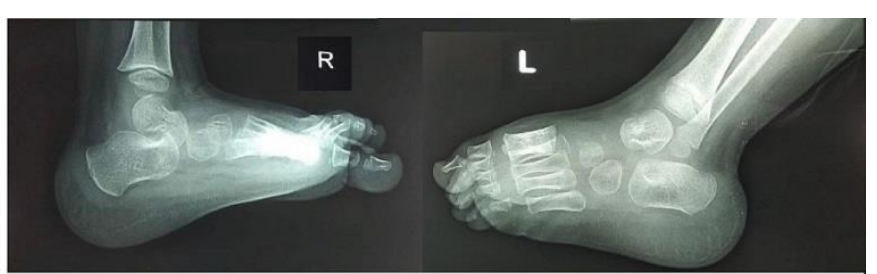

Three year postoperative

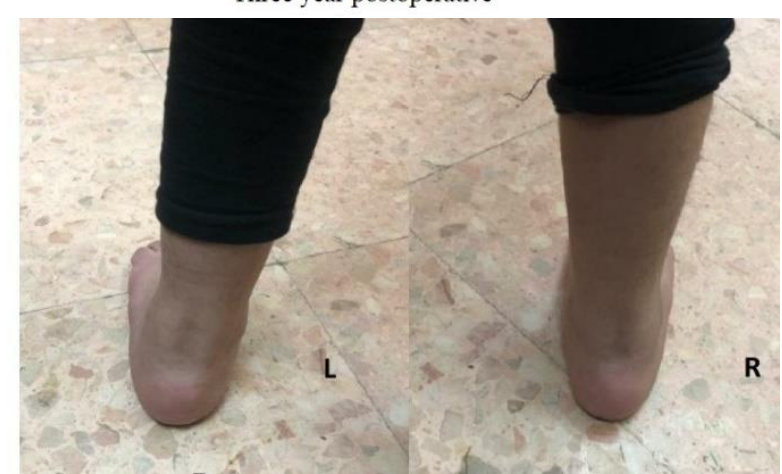

Fig. 5 (A-C): (A) Preoperative non-standing and standing lateral radiographs of a 5-year-old boy with bilateral idiopathic CVT show abnormal indices of the talus. Postoperative radioclinical photos show (B) restoration and maintenance of the indices at immediate and three-year postoperative radiographs. (C) Note the plantigrade feet, restored forefoot and hindfoot alignment.

\section{Naviculectomy versus Talectomy for Complex Congenital Foot: Correlating Concepts}

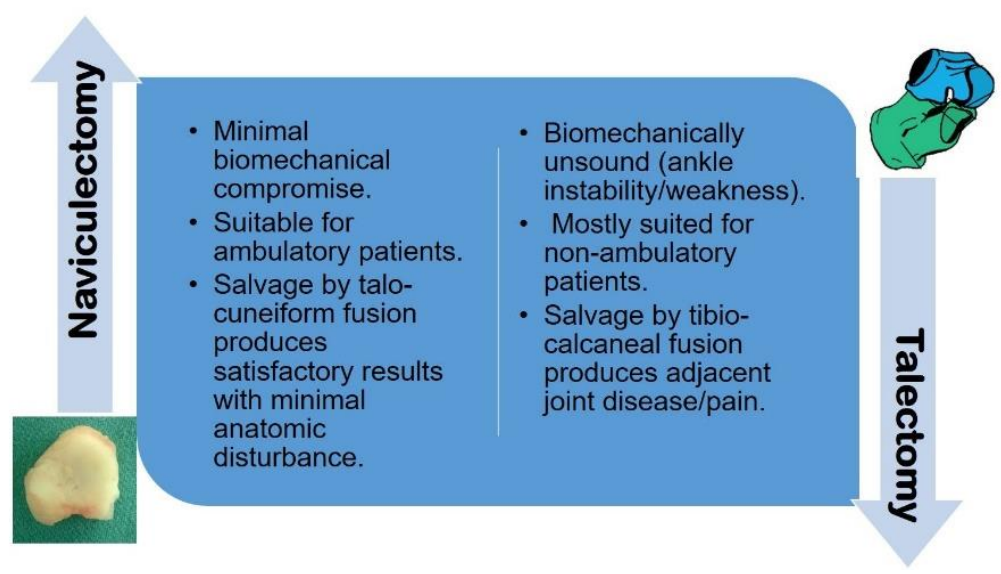

Fig. 6: Naviculectomy versus talectomy: correlating concepts. 
Page 8 of 8

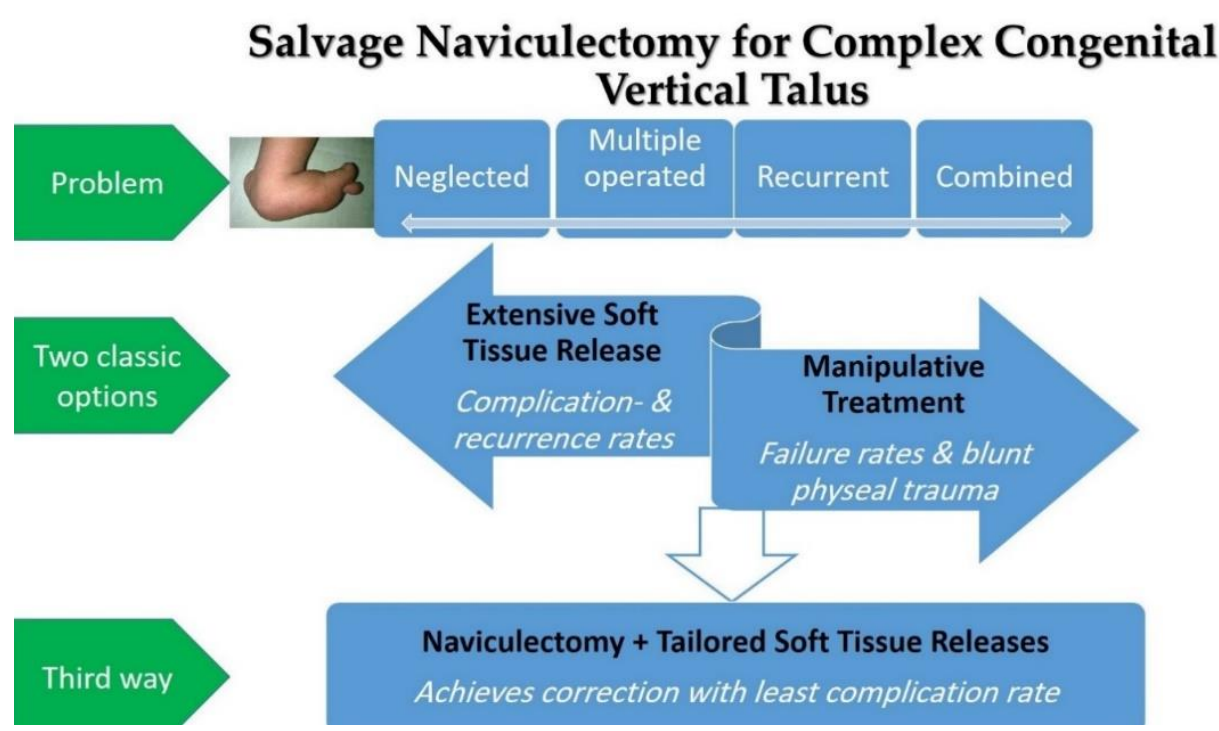

Fig. 7: Naviculectomy in congenital vertical talus. 